\title{
Corrosion Behavior of a Carbon Network/Aluminum Matrix Porous Composite in Salinated and Acidic Environments
}

\author{
Eric M. Eisenhauer and Yong X. Gan * \\ Department of Mechanical Engineering, College of Engineering, California State Polytechnic University Pomona, \\ 3801 W Temple Avenue, Pomona, CA 91768, USA; emeisenhauer@cpp.edu \\ * Correspondence: yxgan@cpp.edu
}

Received: 18 March 2019; Accepted: 24 May 2019; Published: 1 June 2019

check for updates

\begin{abstract}
Through this work, a carbon network/aluminum matrix porous composite material was analyzed for its susceptibility to material degradation in sulfuric acid and seawater corrosive media. Simple potentiodynamic electrochemical testing was implemented, and from polarization curves, the Tafel coefficients and exchange current densities were obtained for a comparative analysis. The pseudo exchange current densities for corrosion of the composite material were compared to those found for $\mathrm{Al} 1235$ and 6061-T6. By relating the pseudo $i_{\text {corr }}$ of these materials in each environment, an understanding regarding the relative propensity to corrosion was determined. According to the recovered data, the composite had the lowest pseudo $i_{c o r r}$ in all corrosion systems and was consequently inferred the least likely to corrode. The factor that primarily contests this conclusion is the material's relatively large exposed surface area. The existence of carbon along the grain boundaries in the $\mathrm{C} / \mathrm{Al}$ composite improved its corrosion behavior. Further discussion concerning the implication of $\beta_{\mathrm{c}}$ is offered. Electrochemical impedance spectroscopic (EIS) tests were performed in the frequency range from $0.001 \mathrm{~Hz}$ to $100 \mathrm{kHz}$. An immersion corrosion test was conducted to calculate the corrosion rate in different environments. Morphological observation on the corrosion surface was also carried out to evaluate the corrosion product deposition on each material.
\end{abstract}

Keywords: porous material; composite; aluminum; carbon network; corrosion; electrochemical kinetics; potentiodynamic polarization

\section{Introduction}

The realm of porous materials has quickly become the subject of much fascination and growth in the areas of noise reduction [1-4], heat transfer [5-7], filtration [8,9], and aeration [10], as well as light-weight structural components [11]. Foamed and porous aluminum are specifically interesting for their exceptional advantages in low density and energy absorption, making them aptly relevant to the provided applications. However, an understanding of porous aluminum and porous aluminum composite's corrosion behavior is essential to ensuring their integrity as mechanical elements in commercial products. In this work, a powder metallurgy-fabricated carbon network/aluminum matrix $(\mathrm{C} / \mathrm{Al})$ porous composite was examined for its resistance to corrosion. This was accomplished via a comparison of its pseudo exchange current density of corrosion $\left(i_{\text {corr }}\right)$ to that of aluminum alloy 6061-T6 and 1235 in various environments. Dynamic polarization curves were generated from the kinetic interactions of these materials in solutions of seawater at $6 \%$ salinity and sulfuric acid at $0.2 \mathrm{~N}$ and $0.1 \mathrm{~N}$. The resulting conclusions prove useful by corroborating the benefit of the inclusion of a carbon network within a porous aluminum structure via the manufacturing methods described in Reference [12]. Aqueous corrosion is referred to as the degradation of a material via a reduction/oxidation reaction with 
the environment, attendant to the formation of cations, leading to the loss of engineering function [13]. All testing and analysis were conducted under this description for corrosion in a wetted setting. Further, uniform corrosion is a thermodynamically driven process that can be determined spontaneous by the Gibb's Free Energy relationship, in using a given metal's standard electromotive force potential, which is related to the standard hydrogen electrode (SHE) [13]. Uniform corrosion is a highly important type of chemical deterioration because it acts on the entirety of a metal's exposed surface area. Its presence is expected in most corrosion systems, given the mechanical components exposure to an aqueous surrounding of which it is susceptible. The potential for other corrosion phenomena is dependent on the component's interaction with other metals, potentials, temperature, and stresses [13].

Electrochemical kinetics can be used to analyze the uniform corrosion of a specific system through kinetically polarizing a metal as both anode and cathode. This is known as cathodic/anodic or dynamic polarization and can be accomplished potentiostatically or galvanostatically. Potentiodynamic polarization testing requires an induced potential for the recording of current per unit area noted as exchange current densities. As opposed to the use of thermodynamics, which provides a probability for corrosion, kinetics offers the determination of a corrosion rate through the process described in ASTM G59 [14]. Of the available parameters in mixed-potential theory, the output current densities are a fundamental aspect of the corrosion system's degradation rate $(C R)$. This is because a larger $i_{\text {corr }}$, and pseudo $i_{\text {corr }}$, most often infers a larger $C R$ relative to other materials tested in the same environment. The pseudo $i_{\text {corr }}$ of each metal/electrolyte corrosion cell provides a basic mode of contrast for suggesting a material's vulnerability to uniform corrosion. By this method, the corrosion behavior and integrity of a product exposed to a given environment can be deduced [13].

As with the various forms of corrosion, there are also different aqueous environments. As derived from the possible applications which could involve the C/Al composite, salinated and acidic surroundings can be considered extreme cases. These environment types are aggressive, by way of leading to early oxidation, which provides the benefit to understanding their effect on the porous material. Aluminum's inability to produce a passive oxide layer in concentrated sulfuric and hydrochloric acid is significant for future studies of porous aluminum protection against corrosion [13].

Salinated environments, such as seawater, can have a detrimental effect on the surface of a metal and is a specific problem for mechanical components at or near coastlines. The presence of salt in the corrosion system acts within the electrolyte to make more ions available for electron transfer. This increases the efficiency of the oxidation reaction on the exposed surface and leads to more rapid degradation [13]. The incidence of chlorine can remove some metals' passive layer, but an alumina coating is unaffected [13]. The consequence of an acidic solution on the integrity of a metal is similar to a salinated one. However, when an acid is present in the environment, it expels excess hydronium $\left(\mathrm{H}^{+}\right)$ into the electrolyte. If no stronger oxidizing agent is present, then $\mathrm{H}^{+}$becomes the primary oxidizer. Thus, the added $\mathrm{H}^{+}$increases the oxidation rate by way of increasing the available oxidizer, meaning more surface metal can be oxidized within the same time period [13]. These corrosion mechanisms are present in the electrochemical cells of this work's experiment.

Of the common metals used as mechanical components, aluminum is particularly unique for its low density to strength ratio [15]. Both its mechanical and chemical properties show its promise as an ideal porous metal. Aluminum, and its alloys, are generally resistant to chemical attack that would cause active corrosion in normal working environments. Exposure of aluminum to common corrosive environments causes instantaneous oxidization and the development of a passive oxide surface layer [13]. Under specific conditions of $\mathrm{pH}$ and potential, $\mathrm{Al}$ will actively corrode. These values are given as a $\mathrm{pH}$ less than four or greater than seven and potentials above $-1.75 \mathrm{~V}$; refer to $\mathrm{Al}^{\prime} \mathrm{s}$ Pourbaix diagram in Reference [16]. This occurrence is possible in the applications provided and therefore offers the grounds for additional corrosion prevention techniques. A common form of corrosion deterrence is coating the material surface with a nobler one [13]. In the case of this work, the carbon network of the C/Al composite can be viewed as a coating on the Al matrix [12]. 
Within the area of study of porous materials, the importance of pore size and shape cannot be understated. These materials can be designed to exhibit an assortment of characteristics that are significantly different from their bulk forms. This aspect of porous materials is outlined by their pore geometry, which may be modified to fit specific criteria [17]. One of the processes used to manufacture reliable porous aluminum structures is described in Reference [17]. It suggests the benefit of Lotus type pores, which are cylindrically shaped via a directionally controlled fabrication method. This increases the structural integrity in the pore axial direction relative to the common spherical type pore [17]. The pore geometry of the $\mathrm{C} / \mathrm{Al}$ composite is a matrix of nonhomogeneous and intermittently connected spherical pores with properties that fluctuate between specimens [12]. Highly reproducible pore geometries are important to a material's technology development because they offer design precision and can lead to accurately modeled representations of material degradation behavior.

\section{Materials and Experimental Methods}

The details for the powder metallurgical method that was used to produce the C/Al composite are detailed in Reference [12]. Aluminum powders were used at a nominal size of $30 \mu \mathrm{m}$ and granulated white $\mathrm{C} \& H$ sugar was used as a spacer and sieved to less than $45 \mu \mathrm{m}$. A green compact was thereafter produced following the mixture of $10 \mathrm{~g}$ of sugar and aluminum powder, at a composition of Al: sugar $=1: 0.5$, under a pressure of $40 \mathrm{MPa}$ [12]. The resultant circular disk had a diameter of $25 \mathrm{~mm}$, with a thickness of $4 \mathrm{~mm}$, and retained these dimensions through the remainder of the procedure. Following the construction of the powder compact, it was placed in a quartz tube for sintering. The tube was moved to a furnace and heated at a rate of $5{ }^{\circ} \mathrm{C} / \mathrm{min}$ until reaching $500{ }^{\circ} \mathrm{C}$. The disk was then sintered at this temperature for $2 \mathrm{~h}$ before furnace cooling to ensured material stability. The subsequent composite morphology exhibited a porous structure of aluminum intermingled and impregnated by a carbon network [12]. During this work's testing, the composite was submerged in solution to a depth of $10 \mathrm{~mm}$, resulting in an active area of $7.45 \mathrm{~cm}^{2}$.

Along with the cellular composite, the experiment also used two separate types of aluminum as modes of comparison. A sample of pure aluminum in the form of foil, aluminum 1235, was taken and submerged at a rectangular area of $1.50 \mathrm{~cm}^{2}$ [15]. Data was thereafter collected from a flat bar of aluminum $6061-\mathrm{T} 6$ with a constituent composition of: $97.90 \mathrm{wt} \% \mathrm{Al}, 1.00 \mathrm{wt} \% \mathrm{Mg}, 0.60 \mathrm{wt} \% \mathrm{Si}$, $0.28 \mathrm{wt} \% \mathrm{Cu}$, and $0.20 \mathrm{wt} \% \mathrm{Cr}$. [18]. The specimen was situated into each experimental solution at $18 \mathrm{~mm}$, at $18 \mathrm{~mm}$ in width and $2 \mathrm{~mm}$ in thickness, leading to a total submerged area of $7.02 \mathrm{~cm}^{2}$.

The environments used in this work include sulfuric acid at $0.2 \mathrm{~N}$ and $0.1 \mathrm{~N}$, as well as seawater with $6 \%$ salt content. An initial solution of $\mathrm{H}_{2} \mathrm{SO}_{4}, \mathrm{R}-0736 \mathrm{G}$ containing only $5 \%$ at full concentration, was diluted about 0.15 times to create a concentration of $0.2 \mathrm{~N}$. After experimentation, the same solution was again diluted by half with DI water to serve as the $0.1 \mathrm{~N}$ environment for the proceeding test. The seawater used here was gathered from Venice Beach, California, U.S. to stand as a representation of what the composite would encounter if implemented at or near a coastline. A salinity of $6 \%$ refers to the seawater from this location with $34 \%$ salt. The chemical ion contributions of salt from greatest to least are as follows: $\mathrm{Cl}, \mathrm{Na}, \mathrm{SO}_{4}{ }^{2-}, \mathrm{Mg}, \mathrm{Ca}, \mathrm{K}, \mathrm{HCO}^{3-}, \mathrm{Br}^{1-}, \mathrm{BO}_{3}{ }^{3-}, \mathrm{Sr}$, and $\mathrm{F}_{2}$. From this, the greatest ionic contributions to corrosion were $\mathrm{Cl}(19.35 \%$ o $), \mathrm{Na}(10.75 \%$ o $), \mathrm{SO}_{4}{ }^{2-}(2.70 \%$ o), and $\mathrm{Mg}(1.30 \%$ o $)$ [19].

The potentiodynamic electrochemical test executed in this work only rudimentarily followed that of the standard test and reduction described in ASTM G59. The experimental setup is that of a simple cell, similar to that described in Reference [13]. The working electrodes of the experiment were the $\mathrm{C} / \mathrm{Al}$ composite, $\mathrm{Al} \mathrm{1235}$, and $\mathrm{Al}$ 6061-T6 samples. $\mathrm{An} \mathrm{Ag} / \mathrm{AgCl}$ reference electrode acted in solution, as opposed to within a Luggin Capillary. This caused an increase in ohmic resistance within the system from around $2 \mathrm{~mm}$, refer to Reference [14], to $40 \mathrm{~mm}$. A Pt counter electrode was used but was again positioned in the system at an improper distance from the specimen [14]. These incorrect placements were the cause of unwarranted resistance, but were consistent throughout the experiment. The reference and counter electrodes were situated in a 3-hole Teflon cap clamped to the rod of a stamped steel support stand. The working electrode position was tuned on an adjustable clamp ring 
affixed to the same support stand as the Teflon cap. All electrodes were thereafter submerged into $100 \mathrm{~mL}$ of the testing solution. Alligator clips were used as the interface between each electrode and a CHI 440C Electro-Chemical Analyzer with serial \#: A2977. Following a data collection procedure for an individual corrosion system, the solution was replaced, and all components cleaned with deionized (DI) water. Testing for each corrosion system was implemented four separate times to confirm data consistency.

Each test was conducted within the voltage range of $-1 \mathrm{~V}$ and $0.5 \mathrm{~V}$; a larger range is recommended for future experimentation. Outputs of the testing were presented as $\log (\mathrm{i})$ and exchange current densities were taken in $\mathrm{A} / \mathrm{cm}^{2}$. A graphical distribution of the data resulted in the cathodic and anodic polarization curves. These were presented on a semi-log plot of current density $\left(\mathrm{A} / \mathrm{cm}^{2}\right)$ versus potential $(\mathrm{V})$ also referred to as a Tafel plot [13]. These polarization curves for all data were recorded and permitted the extrapolation of Tafel coefficients and pseudo exchange current densities for corrosion as outlined in ASTM G5 and Ref. [13]. The parameters were recorded as: the pseudo potential for corrosion $\left(E_{\text {corr }}\right)$ in $\mathrm{V}$, the pseudo exchange current density of corrosion $\left(i_{\text {corr }}\right)$ in $\mathrm{A} / \mathrm{cm}^{2}$, and the rates of cathodic and anodic reactions ( $\beta_{\mathrm{c}}$ and $\beta_{\mathrm{a}}$ respectively) in $\mathrm{V} / \mathrm{dec}$. The horizontal asymptotic pseudo $E_{c o r r}$ line provided a reference for the extrapolation of a regression line from the most linear portion of the cathodic polarization line whose slope was $\beta_{\mathrm{c}}$. The exchange current density at the point of intersection of these lines was recorded as the pseudo $i_{\text {corr }}$. It was also used as the pivot point for the generation of a regression line between it and the first point of contact from below with the anodic polarization line. The slope of this constructed adjacent line was determined as $\beta_{\mathrm{a}}$.

The electrochemical impedance spectroscopic (EIS) tests were performed in the traditional three-electrode cell containing seawater and sulfuric acid as the electrolytes. The sinusoidal signal was generated by a function generator supplied by PASCO, Roseville, CA, USA. The frequency range used was from $0.001 \mathrm{~Hz}$ to $100 \mathrm{kHz}$. An EXTECH LCR meter with the model number of 380,193 made by Fotronic Corporation, located in Melrose, MA, USA, was used to measure the impedance during the polarization by the potentials with the frequency control via the function generator. The real part and the imaginary part of the impedance data were recorded and processed using a MatLab code. Immersion corrosion tests on typical specimens were performed at a room temperature of $20^{\circ} \mathrm{C}$. Both optical images and scanning electron microscopic images of the corroded surfaces were captured to reveal the degradation of the materials in seawater and sulfuric acid.

\section{Results and Discussion}

\subsection{Structure and Composition of the C/Al Composite}

The microstructure of the composite is shown by the scanning electron microscopic (SEM) image in Figure 1a. Figure $1 \mathrm{~b}$ is the $\mathrm{X}$-ray diffraction energy dispersive spectrum (EDS) of the composite, which reveals carbon and aluminum as the major elements. As can be seen from Figure 1a, the carbon networks formed in the sintered aluminum. The densification of the aluminum powders is obvious, but still some pores can be found. While the initial powder size is about $30 \mu \mathrm{m}$, the SEM image reveals the densified domains of aluminum in a wide size range from several tens microns to as large as $200 \mu \mathrm{m}$. Figure $1 \mathrm{~b}$ provides the qualitative information about the composition of the composite material. The spectrum reveals the diffraction peaks from three elements. One is aluminum, the other is carbon. Still another is oxygen. Aluminum has the highest peak because it is the major element. Carbon signal comes from the carbon network. While oxygen is a residual element from the decomposition of the sugar and the oxidation of the aluminum powder. 


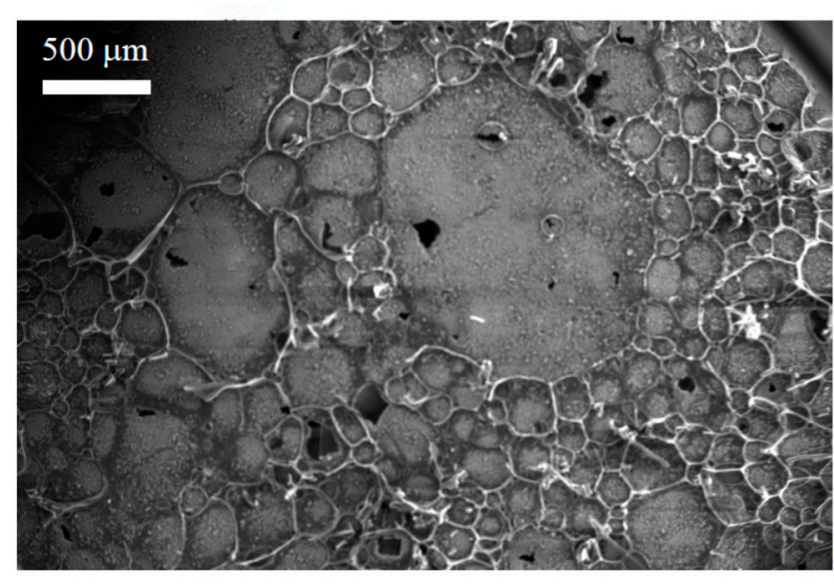

(a)

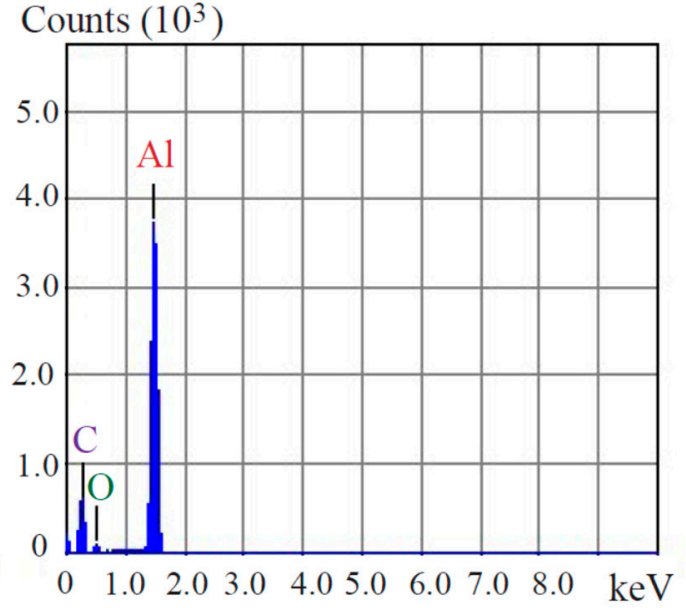

(b)

Figure 1. Scanning electron microscopic analysis results of the porous C/Al composite: (a) SEM image and (b) EDS spectrum.

\subsection{Corrosion Behavior}

A simplified electrochemical test has yielded polarization curves for the $\mathrm{C} / \mathrm{Al}$ composite (see Figure 2), Al 1235 (see Figure 3), and Al 6061-T6 (see Figure 4). An analysis of the corrosion cell kinetics has provided the results listed in Table 1, which consolidates the parameters: Pseudo $E_{c o r r}, \beta_{\mathrm{c}}$, $\beta_{\mathrm{a}}$, and pseudo $i_{\text {corr }}$. These gathered data were used to ascertain an understanding of the corrosion behavior between each environment and material. Pseudo $i_{\text {corr }}$ characterized the composite's corrosion susceptibility as an exchange current density, whereby a relationship among the various systems' relative $C R$ values was established. The influence of the carbon network on the resultant pseudo $i_{\text {corr }}$ was further considered.

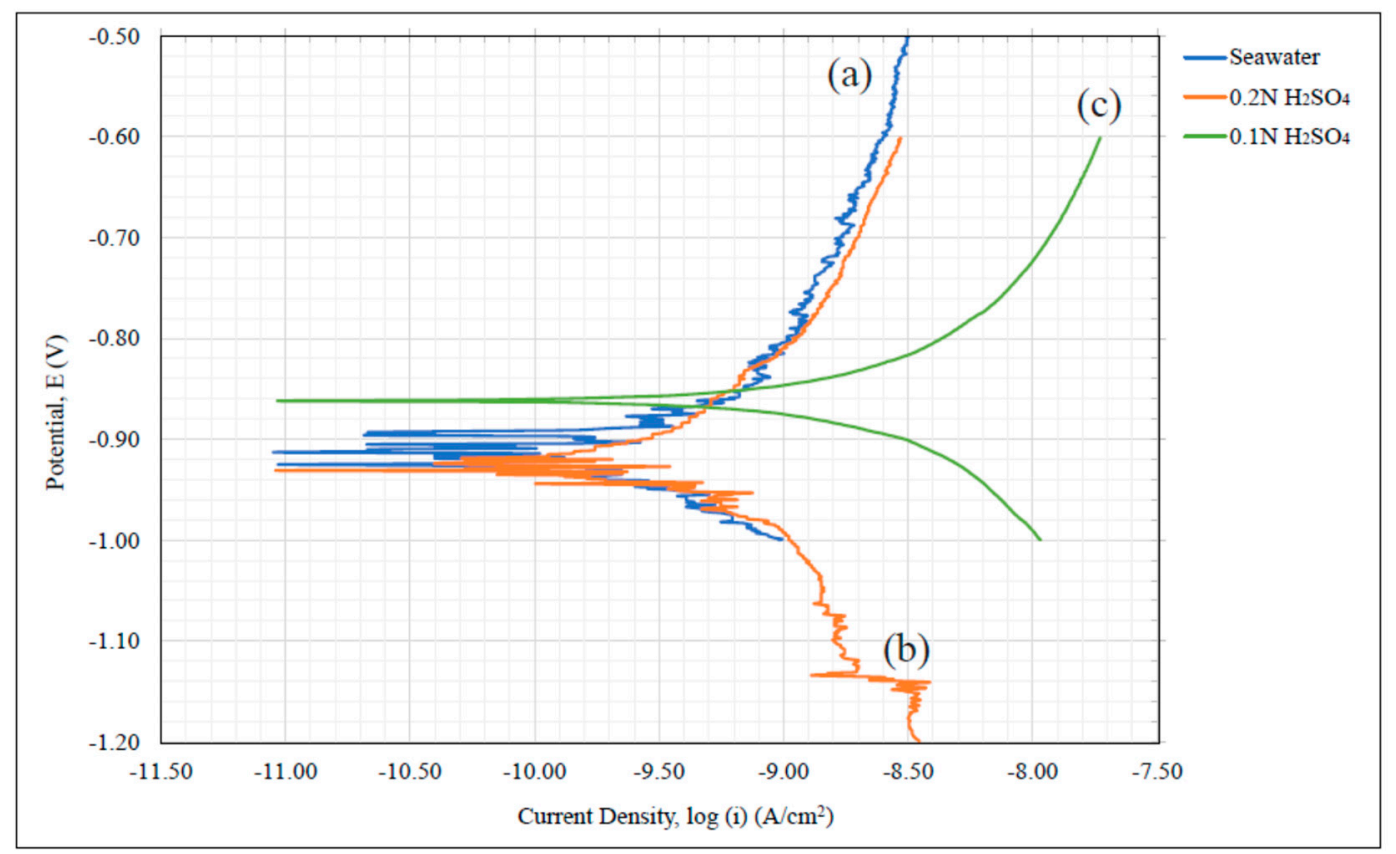

Figure 2. Polarization curves for porous $\mathrm{C} / \mathrm{Al}$ in seawater from $[-1.0,-0.6] \mathrm{V}$ as curve (a), $0.2 \mathrm{~N} \mathrm{H}_{2} \mathrm{SO}_{4}$ from $[-1.2,-0.6] \mathrm{V}$ as curve (b), and $0.1 \mathrm{~N} \mathrm{H}_{2} \mathrm{SO}_{4}$ from $[-0.94,-0.78] \mathrm{V}$ as curve (c). For each curve, a horizontal line may be drawn, which denotes to the location of pseudo $E_{c o r r}$. In addition, positive and negative sloped lines can also be constructed to determine $\beta_{a}$ and $\beta_{c}$ rates, respectively. Finally, a vertical line can be drawn, which provides the pseudo $i_{c o r r}$. Refer to Table 1 for data reduction. 


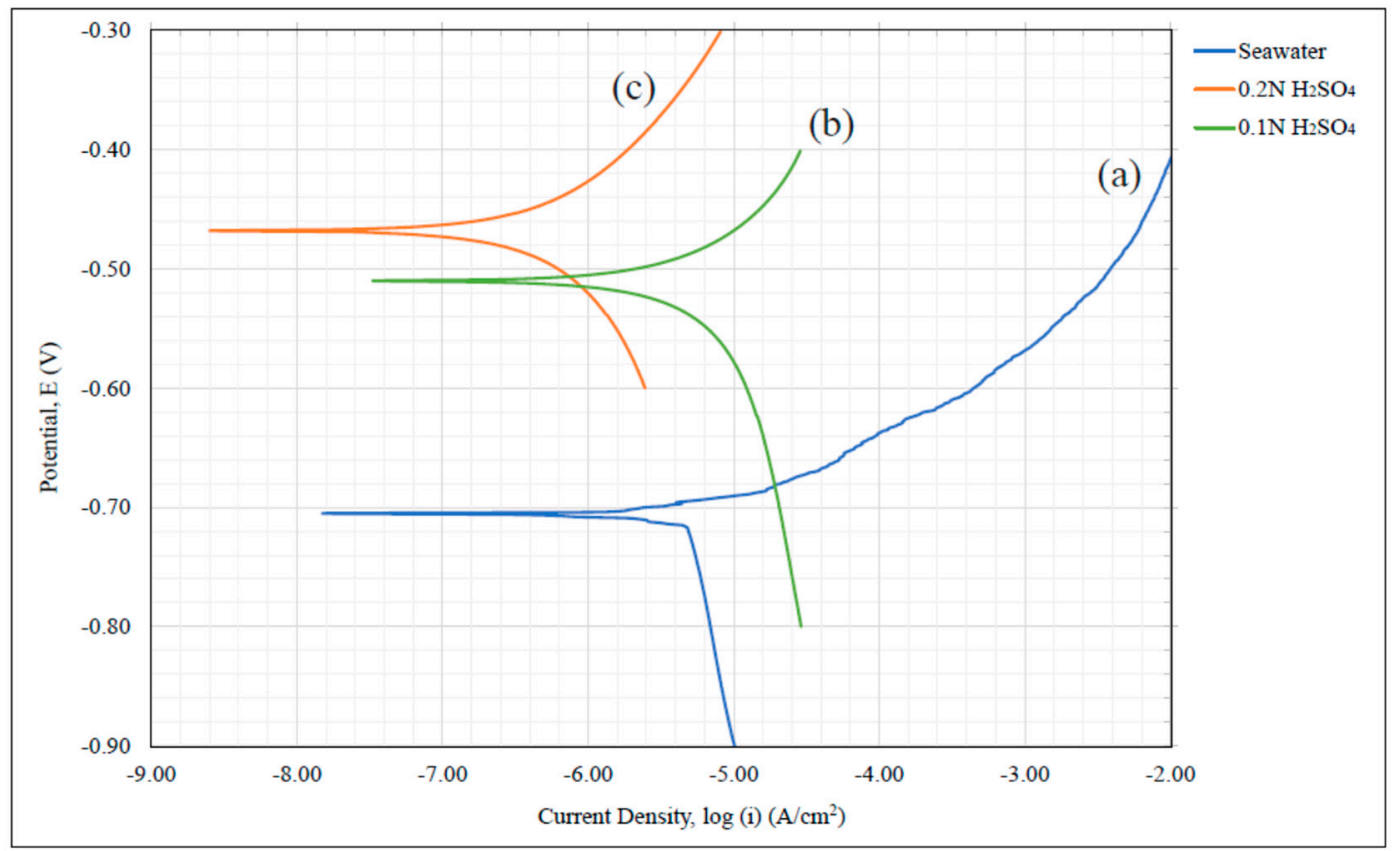

Figure 3. Polarization curves for $\mathrm{Al} 1235$ in seawater from [-0.78, -0.64] V as curve (a), $0.2 \mathrm{~N} \mathrm{H}_{2} \mathrm{SO}_{4}$ from $[-0.54,-0.40] \mathrm{V}$ as shown by curve (b), and $0.1 \mathrm{~N} \mathrm{H}_{2} \mathrm{SO}_{4}$ from $[-0.58,-0.44] \mathrm{V}$ as curve (c). For each curve, a horizontal line may be drawn, which denotes to the location of pseudo $E_{c o r r}$. In addition, positive and negative sloped lines can also be constructed to determine $\beta_{a}$ and $\beta_{c}$ rates respectively. Finally, a vertical line can be drawn, which provides the pseudo $i_{\text {corr }}$. Refer to Table 1 for data reduction.

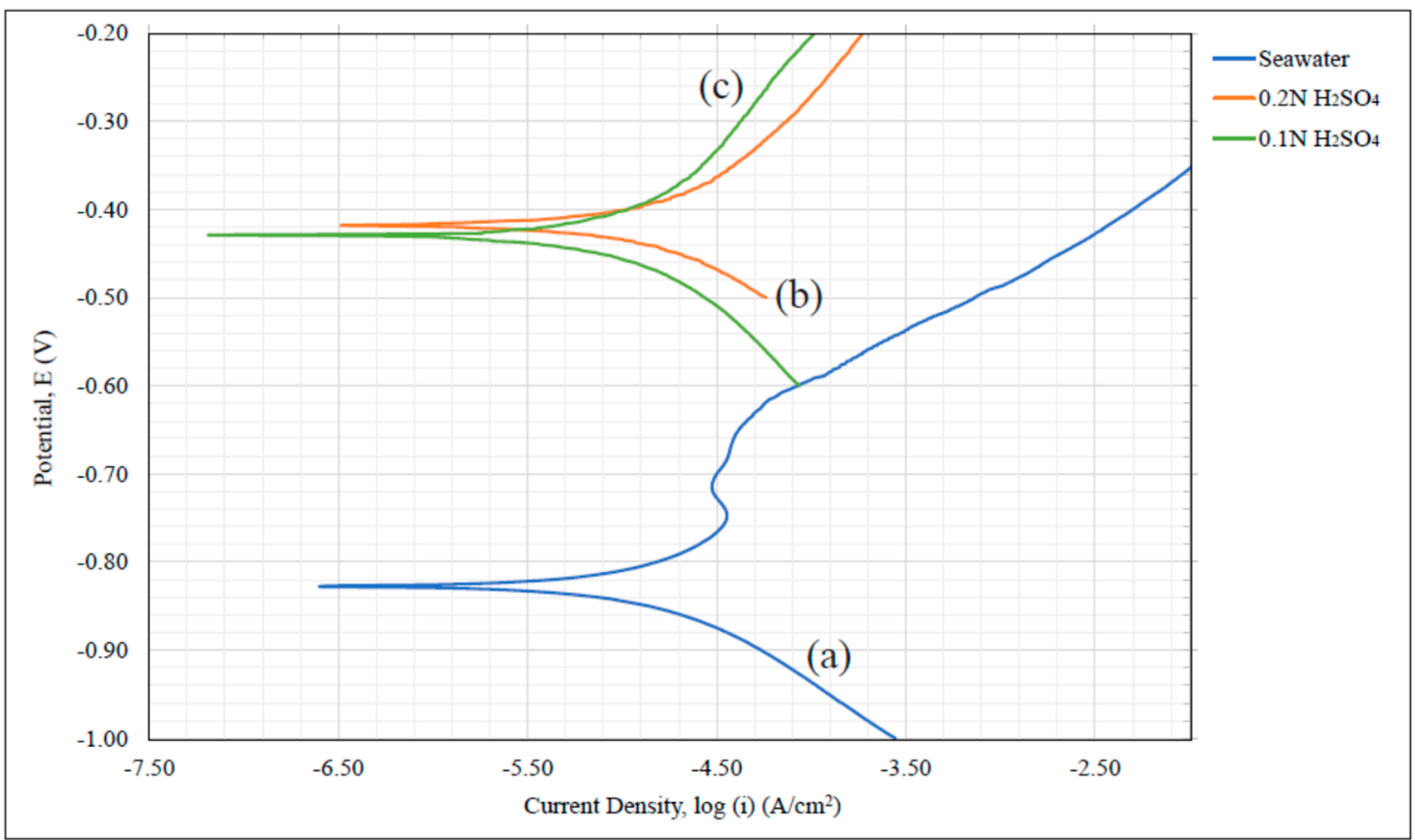

Figure 4. Polarization curves for $\mathrm{Al} 6061-\mathrm{T} 6$ in seawater from [-0.90, -0.76] $\mathrm{V}$ as curve (a), $0.2 \mathrm{~N} \mathrm{H}_{2} \mathrm{SO}_{4}$ from $[-0.50,-0.34] \mathrm{V}$ as curve $(\mathbf{b})$, and $0.1 \mathrm{~N} \mathrm{H}_{2} \mathrm{SO}_{4}$ from $[-0.50,-0.36] \mathrm{V}$ as curve (c). For each curve, a horizontal line may be drawn, which denotes to the location of pseudo $E_{c o r r}$. In addition, positive and negative sloped lines can also be constructed to determine $\beta_{a}$ and $\beta_{c}$ rates, respectively. Finally, a vertical line can be drawn, which provides the pseudo $i_{\text {corr }}$. Refer to Table 1 for data reduction. 
Table 1. Quantitative results from electrochemical analysis and dynamic polarization.

\begin{tabular}{|c|c|c|c|c|}
\hline \multirow{2}{*}{ Electrochemical Cell } & \multirow{2}{*}{ Pseudo $E_{\text {corr }}, \mathrm{V}$} & \multicolumn{2}{|c|}{ Tafel Coefficients } & \multirow{2}{*}{ Pseudo $i_{\text {corr }}, \mathrm{A} / \mathrm{cm}^{2}$} \\
\hline & & $\beta_{\mathrm{c}}, \mathrm{V} / \mathrm{dec}$ & $\beta_{\mathrm{a}}, \mathrm{V} / \mathrm{dec}$ & \\
\hline \multicolumn{5}{|c|}{ Seawater-6\% Salinity } \\
\hline $\mathrm{Al}$ 6061-T6 & -0.827 & -0.106 & 0.137 & $1.12 \times 10^{-5}$ \\
\hline $\mathrm{Al} 1235$ & -0.750 & -0.500 & 0.034 & $4.90 \times 10^{-6}$ \\
\hline C/Al Composite & -0.913 & -0.116 & 0.083 & $1.70 \times 10^{-10}$ \\
\hline \multicolumn{5}{|c|}{ Sulfuric Acid-0.2 N } \\
\hline $\mathrm{Al}$ 6061-T6 & -0.418 & -0.125 & 0.135 & $1.31 \times 10^{-5}$ \\
\hline Al 1235 & -0.468 & -0.138 & 0.103 & $4.07 \times 10^{-7}$ \\
\hline C/Al Composite & -0.928 & -0.308 & 0.340 & $4.89 \times 10^{-10}$ \\
\hline \multicolumn{5}{|c|}{ Sulfuric Acid- $-0.1 \mathrm{~N}$} \\
\hline $\mathrm{Al}$ 6061-T6 & -0.429 & -0.113 & 0.119 & $6.81 \times 10^{-6}$ \\
\hline Al 1235 & -0.510 & -0.170 & 0.104 & $3.98 \times 10^{-6}$ \\
\hline C/Al Composite & -0.862 & -0.135 & 0.145 & $1.62 \times 10^{-9}$ \\
\hline
\end{tabular}

The polarization curves in Figure 2 depict the corrosion kinetics of the porous composite in all environments and reveal behaviors that are corroborated by Reference [12] for seawater, but also extend to the interaction of the material with acidic solutions. The pseudo $i_{c o r r}$ of the C/Al composite was less than the other tested materials in each corrosive solution studied by factors ranging from around $10^{3}$ to $10^{5}$ (see Table 1). This signifies that the composite likely had a significantly lower $C R$ value. The larger exposed surface area, because of the occurrence of pores, seems to not have had any degenerative influence on the material's resistance to deterioration. It is believed that the instance of carbon networking prevented any meaningful corrosion of the aluminum matrix. Further, the non-homogeneity and inconsistency of matrix pore interfacing may have lessened the available surface area for corrosion. In considering $\mathrm{C} / \mathrm{Al}$ composite relative environment behavior, the higher pseudo $i_{\text {corr }}$ indicates that the material was more susceptible to acid containing solutions. A dissimilar pseudo $i_{\text {corr }}$ trend was witnessed for polarization curves given in Figure 3 for $\mathrm{Al} 1235$. The values in Table 1 indicate a larger inferred $C R$ in seawater and at lower acidities rather than higher ones. This error between the pseudo $i_{\text {corr }}$ of the acidic environments may be caused by the oxidation layer removal during the $0.2 \mathrm{~N} \mathrm{H}_{2} \mathrm{SO}_{4}$ testing.

Distinguishable trends of the $\beta_{c}$ and $\beta_{a}$ gathered for the same material, but between different environments, appear to be nonexistent. Generally, these data offer insight regarding the relative rates of oxidation and reduction [13]. From Figure 3, curve (a), a larger $\beta_{c}$ for Al 1235 in seawater, recorded as $0.500 \mathrm{~V} / \mathrm{dec}$ in Table 1 , suggests that it was more responsive to oxidation, whereas the C/Al composite fell within the midrange of reactivity for the materials in question. The respective pseudo $i_{\text {corr }}$ values were expected to comparatively agree with the given $\beta_{c}$. The possibility that this error was caused by prominent noise disturbances, as in Figure 2 curves (a) and (b), from excess ohmic resistance between the electrodes was considered, as the inclusion of a Luggin probe has been shown to minimize this incidence [13]. However, the noise could have additionally resulted from the porous geometry at the surface in which corrosion was taking place. Large fluctuations in resistance could have been caused by interferences in the electrolyte at the pore or are an effect of corrosion over a porous composite material. The overall inclination of the pseudo $i_{\text {corr }}$ values was, however, still consistent with Reference [12]. Additionally, the porous structure allowed for more available oxidization area per its submerged area. This, in conjunction with induced oxygen concentration gradients at the pores, would have amplified the composite's $\beta_{c}$ to levels that outweighed the $\beta_{c}$ of 6061-T6 seen in Table 1. Moreover, the consistency of both $\beta_{c}$ and pseudo $i_{c o r r}$ results seen in the polarization curves of Al 6061-T6 in Figure 4 signifies that the metal was unresponsive to the changes of the given environment. This suggests that the 6061-T6 
sample had a passive oxidation layer on its surface that was unrecognized in polarization curves due to the small voltage range.

Nevertheless, the composite pseudo $i_{\text {corr }}$, consequent exchange current density of the oxidizer $\left(i_{o}\right)$, and inferred corrosion rate $(C R)$, were dwarfed in comparison to the other materials. The cathodic reaction rate tendencies are also recognized in the $0.1 \mathrm{~N} \mathrm{H}_{2} \mathrm{SO}_{4}$ solution but falter with the less diluted sample; $0.2 \mathrm{~N}$. Solution oxidizer differences are not the cause of this occurrence because the oxidizer was held as $\mathrm{H}^{+}$consistently across all environments analyzed. The larger $\beta_{c}$ in the $0.2 \mathrm{~N}$ solution suggests that the $\mathrm{C} / \mathrm{Al}$ composite was more susceptible to oxidation at higher acid concentrations. By comparing the relative difference between the $\beta_{c}$ of $\mathrm{Al} 1235$ and the composite in salinated and acidic solutions, a signification of the composite's higher propensity for oxidization in acidic environments was discovered.

\subsection{Immersion Corrosion Results}

Immersion corrosion tests on both the $\mathrm{C} / \mathrm{Al}$ composite and the 6061-T6 aluminum alloy were performed using the $0.1 \mathrm{~N} \mathrm{H}_{2} \mathrm{SO}_{4}$ and seawater as the solutions. The test set-up is shown in Figure 5 . The weight loss and/or increase with time were recorded to calculate the corrosion rate. Specifically, the weight loss per unit area and unit time was used to evaluate the rate of corrosion. The results of corrosion rate are given in Table 2. It must be indicated that the pure aluminum dissolved very fast in acid. The immersion test was not done for this material. In the later presentation, our focus is on the comparative studies of the C/Al composite material and the Al6061T6 alloy. This is because the comparative study of the two materials is meaningful in delivering some information related to the practical applications of the materials. From the results in Table 2, it can be seen that, in both media, the $\mathrm{C} / \mathrm{Al}$ composite material showed lower corrosion rate than the 6061 aluminum alloy. Both materials had a slightly higher corrosion rates in seawater than in the $0.1 \mathrm{~N} \mathrm{H}_{2} \mathrm{SO}_{4}$.

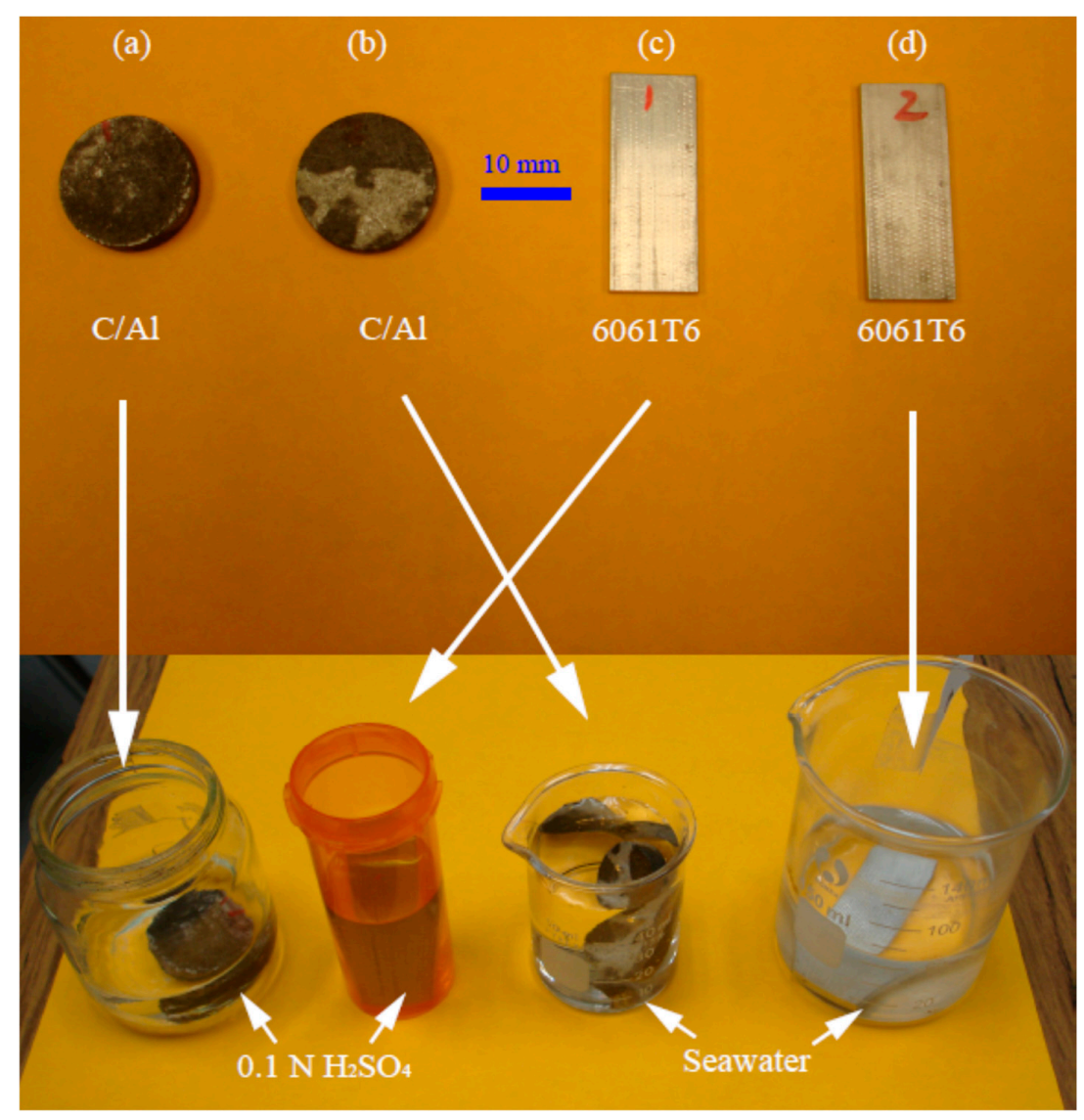

Figure 5. The immersion corrosion test set-up including the specimens and the solutions used. 
Table 2. Corrosion rate results from the immersion corrosion tests.

\begin{tabular}{ccc}
\hline Environment & C/Al Composite Material & 6061 Aluminum Alloy \\
\hline In $0.1 \mathrm{~N} \mathrm{H}_{2} \mathrm{SO}_{4}$ & $2.4286 \times 10^{-4}\left(\mathrm{~g} / \mathrm{cm}^{2} \cdot \mathrm{h}\right)$ & $3.0000 \times 10^{-4}\left(\mathrm{~g} / \mathrm{cm}^{2} \cdot \mathrm{h}\right)$ \\
In Seawater & $2.7143 \times 10^{-4}\left(\mathrm{~g} / \mathrm{cm}^{2} \cdot \mathrm{h}\right)$ & $4.1429 \times 10^{-4}\left(\mathrm{~g} / \mathrm{cm}^{2} \cdot \mathrm{h}\right)$ \\
\hline
\end{tabular}

The surface morphology of the C/Al composite was examined using SEM to show localized corrosion, and the SEM images were shown in Figure 6. To reveal the general morphology of the consequence due to the immersion corrosion test, low magnification optical images were captured and shown in Figure 7. Figure 6a is an image taken from the surface of the $\mathrm{C} / \mathrm{Al}$ specimen after it soaked in $0.1 \mathrm{~N} \mathrm{H}_{2} \mathrm{SO}_{4}$ for a week. It is found that the corrosion occurs inside the grains. The grain boundaries covered by the carbon networks did not corrode. While soaked in seawater for a week, some corrosion products were seen to start piling up on the right-hand side part of the surface as illustrated by the SEM image in Figure $6 \mathrm{~b}$. The corrosion product aggregation is the reason for the specimen weight increase, as observed during the immersion corrosion tests. In either case of the diluted $\mathrm{H}_{2} \mathrm{SO}_{4}$ or the seawater as the corrosion medium, the anodic reaction can be expressed by:

$$
\mathrm{Al} \rightarrow \mathrm{Al}^{3+}+3 \mathrm{e}^{-}
$$

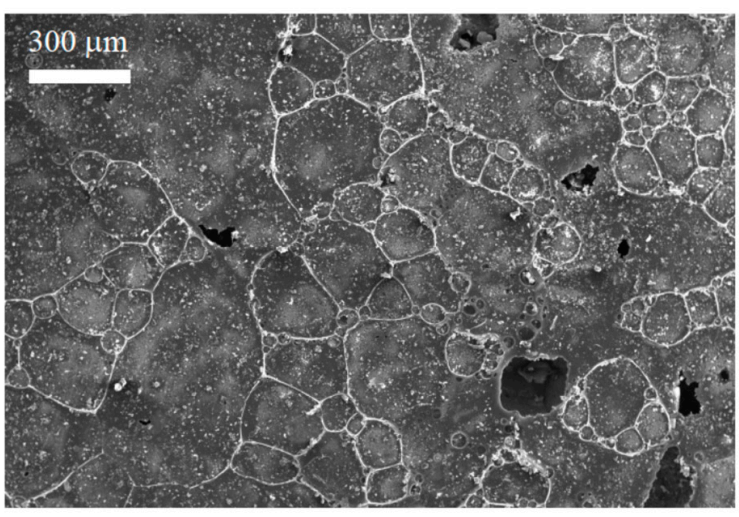

(a)

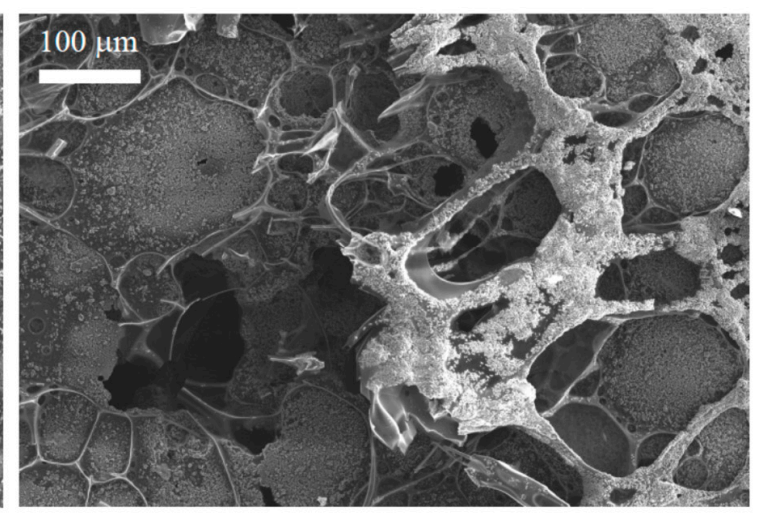

(b)

Figure 6. SEM images taken from the surface of the C/Al composite showing: (a) corrosion development inside the grain due to the active dissolution of aluminum in $0.1 \mathrm{~N}$ sulfuric acid, (b) corrosion product pile-up on the surface of the specimen due to seawater corrosion.

Since the $\mathrm{pH}$ values for seawater are in the range from 7.5 to 8.5 , the cathodic reaction is oxygen reduction, which is shown as:

$$
\begin{gathered}
\mathrm{O}_{2}+\mathrm{H}_{2} \mathrm{O}+4 \mathrm{e}^{-} \rightarrow 4 \mathrm{OH}^{-} \\
6 \mathrm{OH}^{-}+2 \mathrm{Al}^{3+} \rightarrow 2 \mathrm{Al}(\mathrm{OH})_{3}
\end{gathered}
$$

The aluminum hydroxide can be converted into oxide following the reaction, as below:

$$
2 \mathrm{Al}(\mathrm{OH})_{3} \rightarrow \mathrm{Al}_{2} \mathrm{O}_{3}+3 \mathrm{H}_{2} \mathrm{O}
$$

We believe that the corrosion product in solid form should be the mixture of the hydroxide and the oxide. This mixture has poor electrical conducting behavior. The SEM image showed the electron charging feature as the bright zone in the right-hand side of Figure $6 \mathrm{~b}$. 


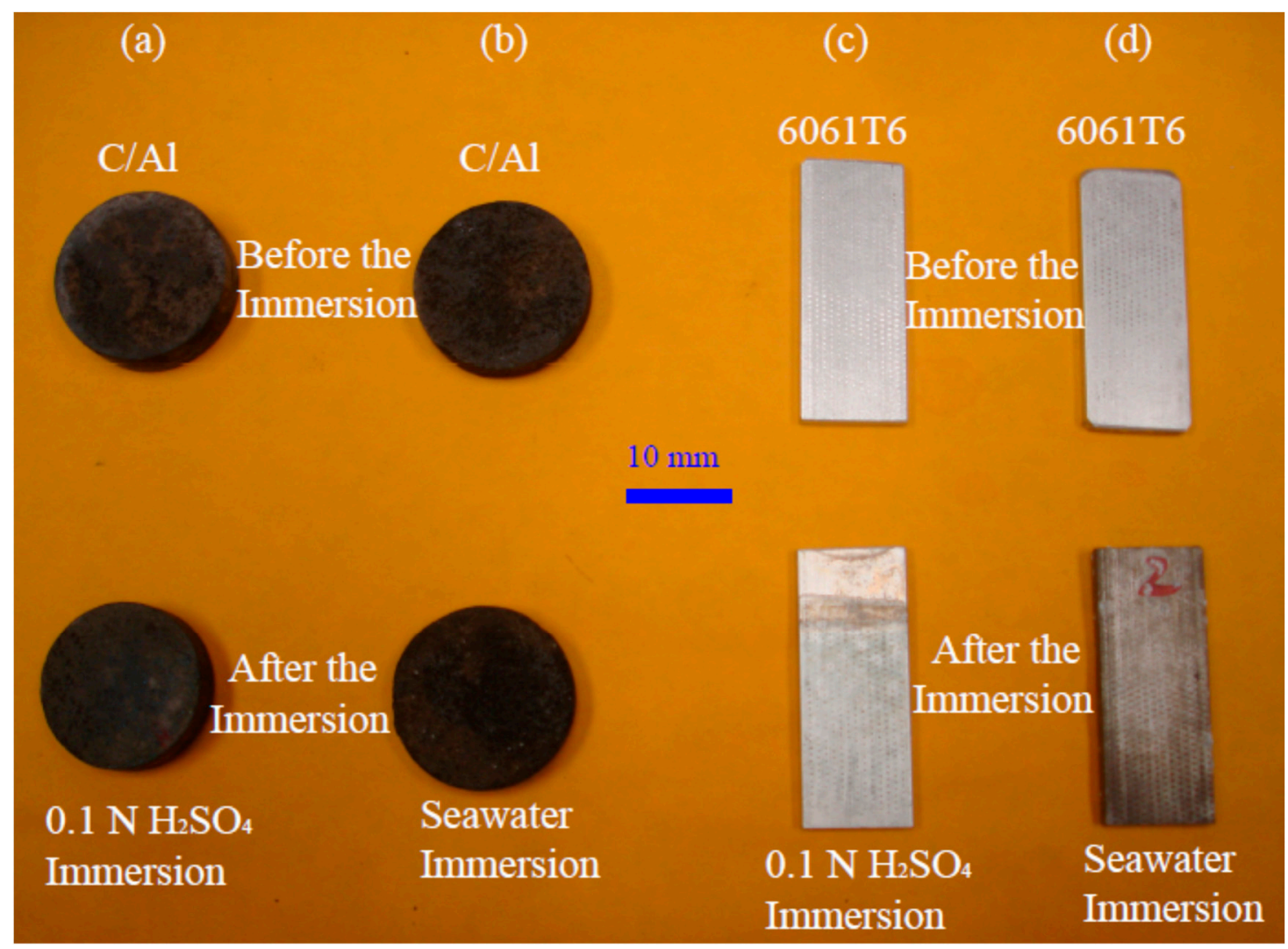

Figure 7. Optical images taken from the surface of the $\mathrm{C} / \mathrm{Al}$ composite and 6061 showing the general morphology of the materials before and after immersion tests: (a) C/Al composite before and after immersion $0.1 \mathrm{~N}$ sulfuric acid, (b) C/Al composite before and after immersion in seawater, (c) 6061 before and after immersion $0.1 \mathrm{~N}$ sulfuric acid, and (d) 6061 before and after immersion in seawater.

\subsection{Effect of Carbon Network}

The influence of the carbon network was a significant parameter of examination in analyzing the susceptibility of the $\mathrm{C} / \mathrm{Al}$ composite to degradation in the seawater and diluted $\mathrm{H}_{2} \mathrm{SO}_{4}$ electrolytes. The data in Table 1 suggests that a substantial variance in the pseudo $i_{\text {corr }}$, between the porous material and the others analyzed, was the result of a corrosion suppression. These results corroborate the understanding in Reference [12] that the sugar, which decomposed to carbon during the manufacturing procedure, acted as a corrosion inhibitor. Passivity during anodic polarization was not signified in the polarization curves, due to high system resistance, but was a prominent feature of the porous material. As suggested in Reference [12], and reflected in this work's analysis, the sugar decomposition yielded a porous composite with a corrosion behavior analogous of graphite in the studied environments. Thus, the carbon network was believed to have surrounded the $\mathrm{Al}$ matrix during manufacture. This greatly enhanced the corrosion resistance of the porous composite relative to its base matrix material aluminum and implies its capability for use in aggressive conditions.

Some discussion can be supplemented regarding the instance of galvanic corrosion through the addition of a $\mathrm{C}$ network to an $\mathrm{Al}$ matrix. The galvanic series suggests that this form of material deterioration was highly probable and could have occurred rapidly due to the large activity difference between $\mathrm{C}$ and $\mathrm{Al}$ [13]. However, the test was performed within the $\mathrm{pH}$ range for $\mathrm{Al}$ passivity and the $\mathrm{Al}$ matrix was most likely not sufficiently exposed to the environment. Additionally, alumina was present on the material surface because the exposed $\mathrm{Al}$ was passivated. Subsequently, the results could not be analyzed for the effect of galvanic corrosion.

It is also worth mentioning that while the effect of the carbon network, by impregnation in the Al matrix, results in a significant relative decrease in the $C R$, the presence of carbon influences the 
material's structural integrity. It is considered that the increased carbon content caused a collapse of the material's post-process geometry with only minimal handling. This was likely caused by the low solubility of carbon in aluminum, which would cause an accumulation of carbon in the aluminum grain boundaries. From this it was determined that the addition of a carbon network negatively impacts ductility, leading to a fragile porous composite. A continued reduction of the carbon content would require a proportional decrease to the pore size, negating the manufacturing purpose.

From the low magnification images in Figure $7 \mathrm{a}, \mathrm{b}$, it is found that the C/Al composite material specimens did not show any obvious change in the general morphology (global view). However, the 6061 aluminum alloy specimens changed surface morphology obviously. In $0.1 \mathrm{~N}$ sulfuric acid, the part of the 6061 specimen immersed in the acid was tarnished as revealed by the last image (the bottom one) in Figure 7c. Seawater seems more aggressive in causing the corrosion of the 6061 alloy, as can be seen from Figure 7d. After the immersion in seawater for a week, the surface changed from bright to dark color. Again the morphological analysis confirms the better corrosion behavior of the C/Al composite material than that of the 6061 aluminum alloy.

\section{Electrochemical Impedance Spectroscopy (EIS)}

During the electrochemical impedance spectroscopic (EIS) tests, a three-electrode cell was used. The reference electrode was the $\mathrm{Ag} / \mathrm{AgCl}$ in $\mathrm{KCl}$ solution. The counter electrode was a platinum wire. The working electrode was either the $\mathrm{C} / \mathrm{Al}$ composite or the 6061 aluminum alloy. $0.1 \mathrm{~N}$ sulfuric acid and seawater were used as the electrolytes for the tests. The polarization potential in sine wave was added between the working electrode and the counter electrode. The impedance between the working electrode and the reference one was recorded. The frequency of the polarization potential changed from $0.001 \mathrm{~Hz}$ to $100 \mathrm{kHz}$. The real part and the imaginary part of the impedance data were plotted to examine the electrochemical reaction mechanisms associated with the corrosion of the materials in both the sulfuric acid solution and seawater.

Figure 8 shows the results from the EIS tests on different materials in the acid and seawater. Obviously, these plots reveal the pure capacitive coating-like behavior. Such a behavior seems reasonable because both materials could form passive coatings in the oxidative acid and in the seawater electrolyte. The seawater has a $\mathrm{pH}$ value close to 7.5 , which allows aluminum to form a passivation layer. While the sulfuric acid is intrinsically oxidative, causing the aluminum alloy to form surface film. The EIS measurement results are also in agreement with the morphological analysis results. Figure $6 \mathrm{a}, \mathrm{b}$ show that the aluminum grains were covered by the carbon networks, while Figure $7 \mathrm{c}$, d reveal that the 6061 aluminum alloy specimens were covered by colored coatings.

The methodologies of this work's tests deviate from the standard model as provided in Ref. [14]. Due to the differences in controlling the corrosion conditions, it is important to mention that the Tafel plot data recovered in this work's testing could generate some errors in calculating the corrosion rate. That is why in this work, we estimated the corrosion rates of the two materials (C/Al and $6061 \mathrm{Al}$ alloy) from the immersion tests. An accurate comparison of the investigated materials- $\mathrm{C} / \mathrm{Al}$ composite, $\mathrm{Al}$ 1235 , and aluminum 6061-T6- kinetic phenomena in each testing solution $-\mathrm{H}_{2} \mathrm{SO}_{4}$ at $0.2 \mathrm{~N}$ and $0.1 \mathrm{~N}$ as well as seawater at $6 \%$ salinity — can only be made consistent by following the procedures in ASTM G59 [14], G3 [20], and G5 [21]. These outline an experimental method and provide a data reduction procedure that uses relationships (1) through (4) of Reference [14] to generate a precise $C R$ value.

The major distinction between the data reduction procedure in this work and that of the standard was the use of the polarization curves and pseudo $i_{\text {corr }}$. This parameter provides a basis of comparison between materials in the same environment, and was only a preliminary suggestion of the true $i_{\text {corr }}$ and $C R$. A future experiment would gather subsequent data of each corrosion system using the polarization resistance $\left(R_{p}\right)$ method. 


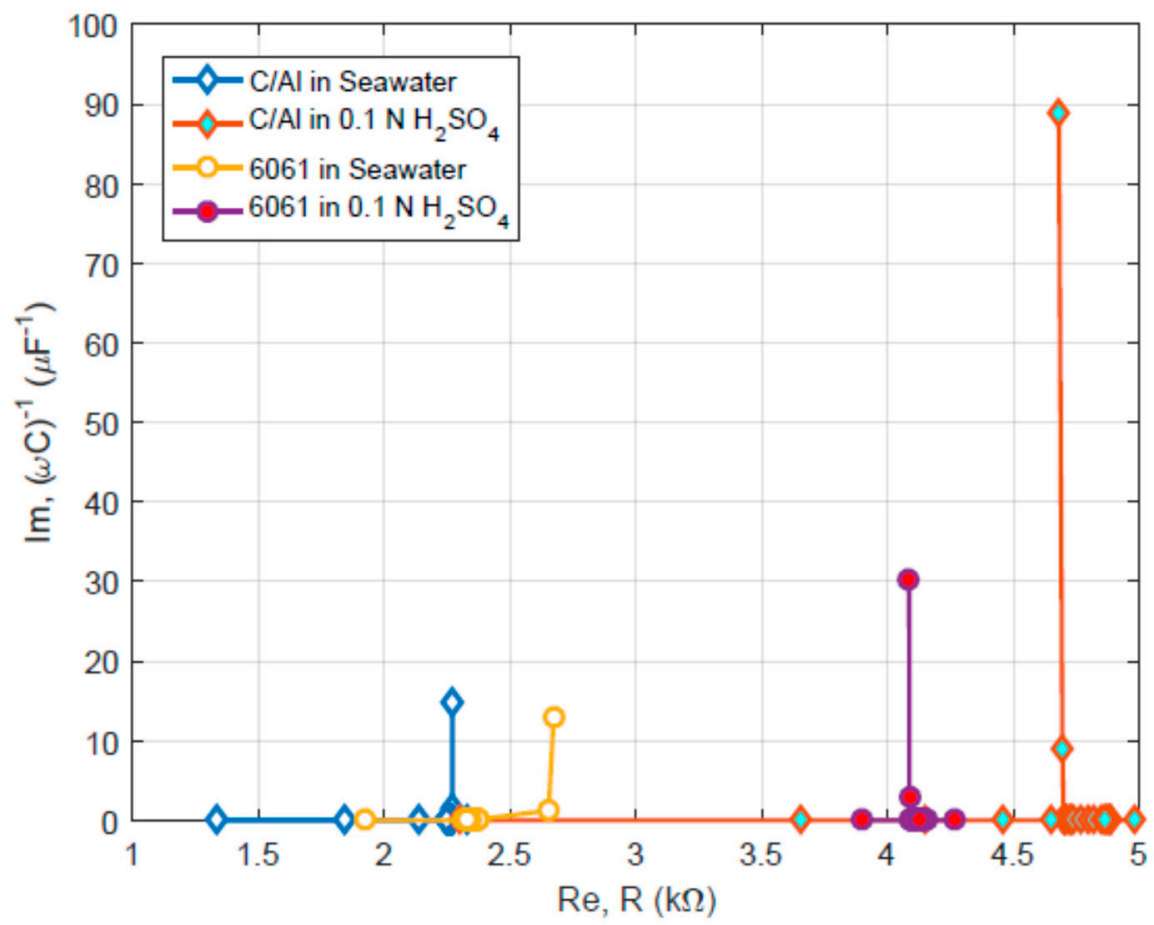

Figure 8. The impedance plots based on the EIS tests on the C/Al composite and 6061 aluminum alloy in sulfuric acid and seawater showing the pure capacitive coating behavior.

In this step, a similar practice to that for developing a dynamic polarization curve would be used. However, only a small potential scan would be applied to the system to prevent over polarization of the working electrode surface [13]. The exchange current density range must also fit within the negative and positive regions. From here, an origin - at the steady state value $0 \mathrm{~A} / \mathrm{cm}^{2}$ and the corresponding true $E_{\text {corr }}$-could be developed and the $R_{p}$ slope, in ohm- $\mathrm{cm}^{2}$, may be determined following the relationship in (1) of Reference [14]. From this complementary information, the true $i_{\text {corr }}$ and $C R$ could be reliably deduced.

Although not within the scope of this work, a comment is added regarding the importance of intergranular graphite to corrosion phenomena. As mentioned earlier, an exposure of the base metal element $\mathrm{Al}$ to an environment that could catalyze active corrosion could generate a galvanic corrosion system of a large potential difference with graphite acting as a highly effective cathode [13]. Additionally, the interaction between $\mathrm{Al}$ and electrolytes could cause oxide growth, via crevice corrosion, that would induce intergranular stresses and cause premature material failure [22]. A recommendation is made for future study of the consequence this and activity difference have on the C/Al composite's longevity in corrosive settings.

It is meaningful to examine the trend of impedance change during the polarization processes. To implement this, the AC voltammetry technique was used in the study. The $\mathrm{CH}$ Instrument Model 440C Electrochemical Workstation was used to generate the polarization signal and to perform the data acquisition. As is known, the AC Voltammetry is capable to analyze the Faradaic impedance. In our work, a low-amplitude sinusoidal voltage with the amplitude of $25 \mathrm{mV}$ is given to the working electrode (the 6061-T6 and C/Al composite). The frequency of the sinusoidal AC voltage is $100 \mathrm{~Hz}$. The work electrode was polarized by increasing or decreasing DC voltages relative to the $\mathrm{Ag} / \mathrm{AgCl}$ reference electrode. Because of the difference in the time scale, the AC component of the total current can be readily differentiated from the DC component. During the test, the total current, the scanning potential, the in-phase current and the out-of-the-phase current were recorded. The data were used to generate the polarization curves and the electrochemical or Faradaic impedance. 
Figure 9 shows the $\mathrm{AC}$ voltammetry and the electrochemical impedance results based the test for the 6061-T6 aluminum alloy in $0.1 \mathrm{~N} \mathrm{H}_{2} \mathrm{SO}_{4}$. Figure 9a is the cathodic polarization curve that is corresponding to the downward sweep scan with the potential decreasing from $-0.2 \mathrm{~V}$ to $-1.0 \mathrm{~V}$. While Figure $9 \mathrm{~b}$ represents the anodic polarization curve with the potential increasing from $-1.0 \mathrm{~V}$ to $0.2 \mathrm{~V}$. In the tests for generating both sub-plots, the sinusoidal signal was superposed onto the linear DC scanning potential. In Figure $9 a$, a peak located between -0.9 and $-0.7 \mathrm{~V}$ was found. In Figure $5 b$ the peak slightly shifted to the range from -0.8 to $-0.6 \mathrm{~V}$. The corrosion potential of the aluminum alloy, as shown in Figure 2 curve (c), falls into the potential range, as revealed by Figure $9 a, b$. This indicates that the electrochemical reaction of 6061 corrosion in $0.1 \mathrm{~N}$ sulfuric acid can be detected by the Taefl method and the AC voltammetry.

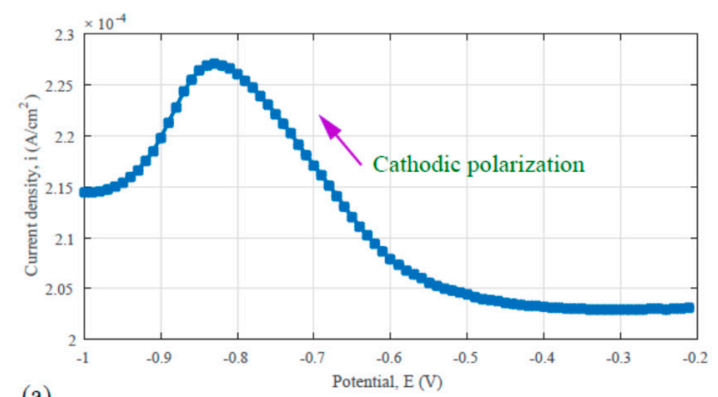

(a)

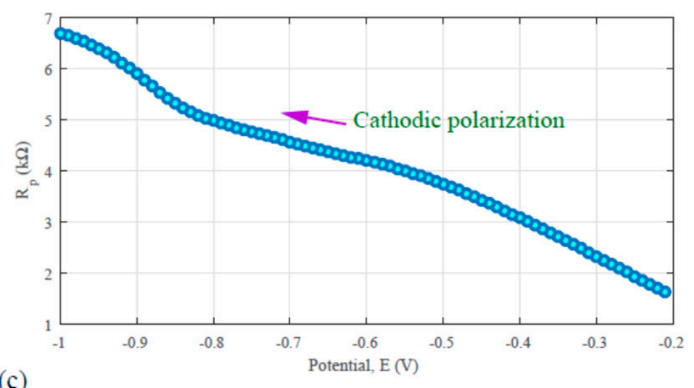

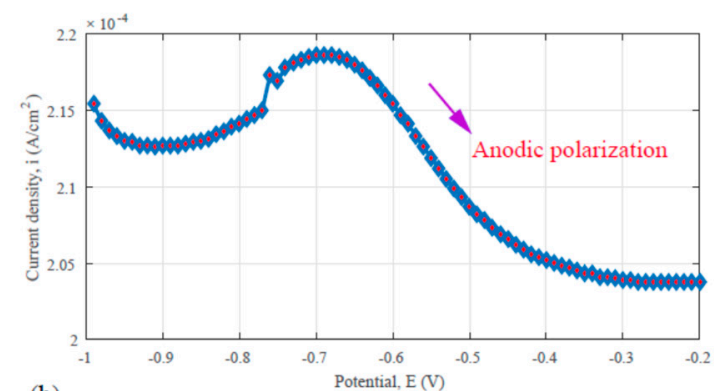

(b)

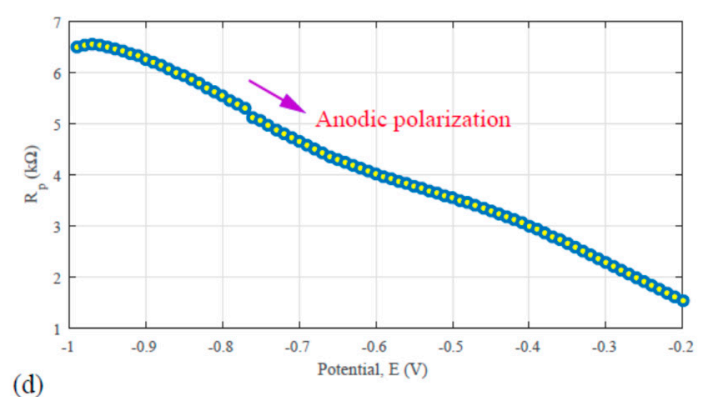

(d)

Figure 9. AC voltammograms and electrochemical impedance plots of the 6061-T6 aluminum alloy in $0.1 \mathrm{~N}$ sulfuric acid: (a) Voltammogram generated by the cathodic polarization (downward sweep), (b) voltammogram generated by the anodic polarization (upward sweep), (c) impedance versus scanning potential in the cathodic polarization, and (d) impedance versus scanning potential in the anodic polarization.

Evaluation of the reaction resistance was made. The results as shown in Figure $9 \mathrm{c}$ come from the division of the scanning potential by the corresponding in-phase current during the downward sweep or cathodic polarization cycle. While the results, as shown in Figure 9, stand for the division of the scanning potential by the corresponding in-phase current during the upward sweep or anodic polarization cycle. The electrochemical impedance of the system reached a value between 4 and $5 \mathrm{k} \Omega$. Comparing with the EIS results shown in Figure 8 was made. In Figure 8, the real part of the impedance ranges from 3.9 to $4.3 \mathrm{k} \Omega$, which is slightly lower than the results from Figure $9 \mathrm{c}$ or d.

For the porous $\mathrm{C} / \mathrm{Al}$ composite material in $0.1 \mathrm{~N}$ sulfuric acid, the similar AC voltammetry test as for the Al6061-T6 was performed also. The results are shown in Figure 10. In Figure 10a, the cathodic polarization or downward sweep curve reveals two peaks in the potential range from -1.2 to $-0.5 \mathrm{~V}$. In the reversed scan, anodic polarization (upward sweep), multiple peaks were also found, as illustrated by Figure 10b. These peaks indicated the complexity of electrochemical reactions in the corrosion of the $\mathrm{C} / \mathrm{Al}$ composite material. Aluminum dissolution is one of the major reactions. In addition, water oxidation and oxygen reduction at the carbon network surface could happen. Nevertheless, the exact reaction mechanisms and kinetics remain to be studied in more detail. 


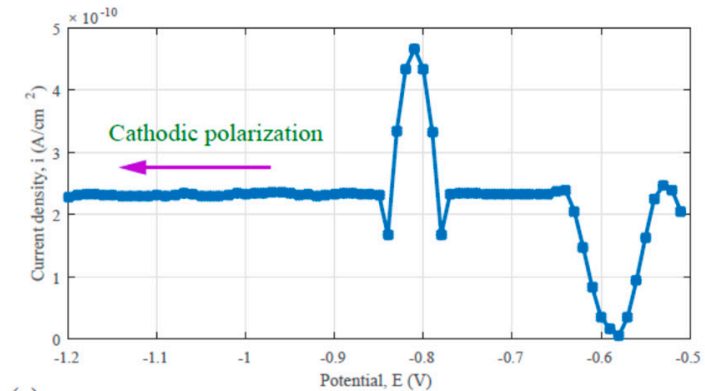

(a)

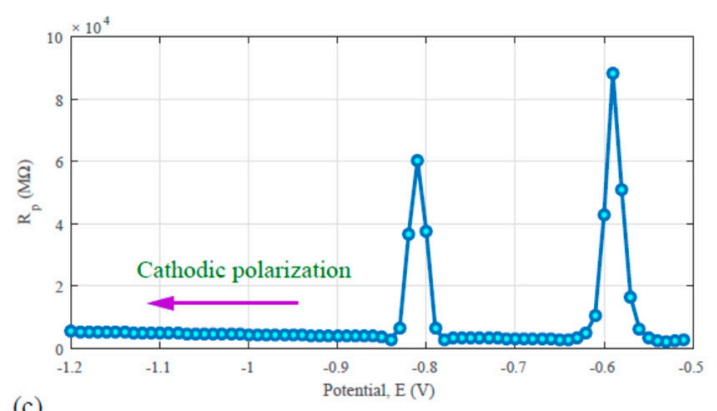

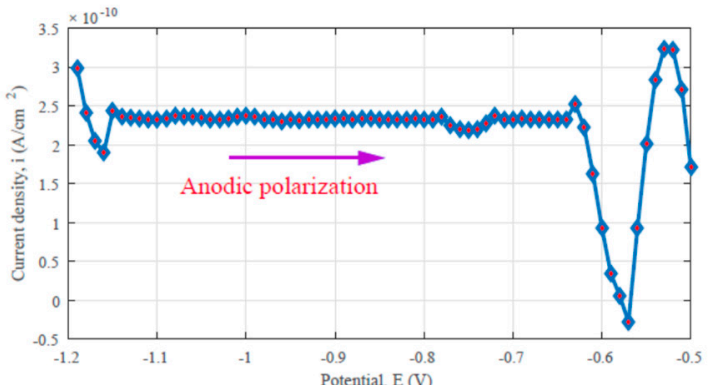

(b)

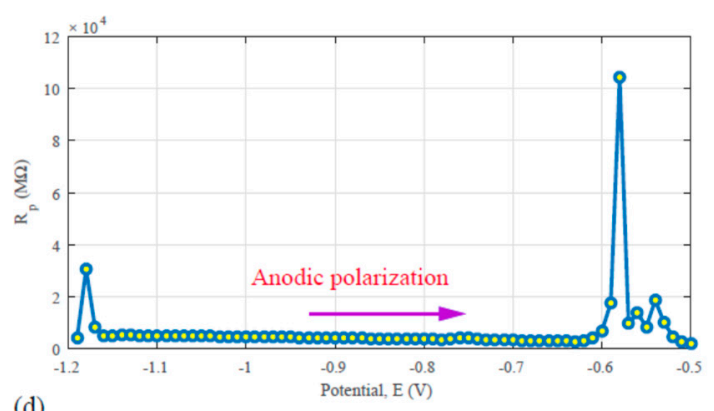

(d)

Figure 10. AC voltammograms and electrochemical impedance plots of the $\mathrm{C} / \mathrm{Al}$ composite material in $0.1 \mathrm{~N}$ sulfuric acid: (a) Voltammogram generated by the cathodic polarization (downward sweep), (b) voltammogram generated by the anodic polarization (upward sweep), (c) impedance versus scanning potential in the cathodic polarization, and (d) impedance versus scanning potential in the anodic polarization.

Figure 10c is a plot obtained by dividing the in-phase current from the scanning potential during the downward sweep or cathodic polarization cycle. Figure 10d stand for the division of the scanning potential by the corresponding in-phase current during the upward sweep or anodic polarization cycle. The electrochemical impedance of the C/Al composite- $0.1 \mathrm{~N}$ sulfuric acid system as obtained from Figure 10c or $\mathrm{d}$ is much higher than that of the Al6061-T6-0.1 N sulfuric acid system, as shown in Figure $9 \mathrm{c}$ or $\mathrm{d}$. Such a difference in the impedance reflects that the electrochemical reaction resistance for the two materials is not the same when they are exposed to the acidic environment. The higher the electrochemical impedance, the higher the corrosion resistance. Obviously, the C/Al composite material has a better corrosion property than the Al6061-T6 alloy.

\section{Conclusions}

A carbon network/aluminum matrix porous composite material was analyzed for its susceptibility to corrosion using dynamic polarization testing and data of electrochemical kinetics. Pseudo $i_{\text {corr }}$ values where taken as a means of inferring potential corrosion rate and as a mode of comparison between the composite, $\mathrm{Al} 1235$ data, and 6061-T6 in seawater at $6 \%$ salt content and sulfuric acid at $0.2 \mathrm{~N}$ and $0.1 \mathrm{~N}$. The Tafel coefficients $\beta_{c}$ was also used to understand the influence of the carbon network on the disposition of the oxidizer $\mathrm{H}^{+}$to react with the porous composite surface. The instance of a larger $\beta_{c}$ for the composite was found to be an effect generated by porous geometry and testing environment, but did not directly compare to pseudo $i_{\text {corr }}$. An evaluation of the pseudo $i_{\text {corr }}$ data revealed that the composite exhibited the lowest value in all environments studied. From the relationship between this information and the material's rate of oxidation, it was inferred that the C/Al composite's corrosion rate was substantially lower than the other materials. This was attributed to the high intergranular carbon content created within the porous aluminum structure during its production process. The introduction of a carbon matrix induced a $\mathrm{C} / \mathrm{Al}$ composite corrosion behavior similar to graphite even when exposed to acidic environments. This suggests that significantly reduced corrosion rates can be achieved for a porous aluminum and shows that the manufacturing approach of Reference [2] can be utilized 
to produce a porous aluminum composite that is more corrosion resistant than its base aluminum matrix material.

The corrosion susceptibility of the C/Al material was also found to be dependent on the given carbon content. However, Ref. [2] showed that variations in the Al: sugar ratio caused smaller pore size or material embrittlement. Consequently, the C/Al composite was not justified as a light-weight structural material. Although, with a behavior comparative to graphite, the material's relevance to low energy absorption applications that include an inevitable exposure to deteriorative environments is noted.

Additionally, it was discovered that the electrochemical cells of this work's experiments were characteristic of fundamentally high ohmic resistances. This produced a reasonable bias error that skewed the data and led to an unrepresentative presentation of the true corrosion kinetics for each electrochemical system. A reliable definition of each material's corrosion behavior by corrosion rate is necessary before the results and conclusions can be verified.

Author Contributions: Data curation, E.M.E.; Formal analysis, E.M.E.; Funding acquisition, Y.X.G.; Investigation, E.M.E.; Methodology, Y.X.G.; Project administration, Y.X.G.; Resources, Y.X.G.; Supervision, Y.X.G.; Writing—original draft, E.M.E.; Writing—review \& editing, Y.X.G.

Funding: This research was funded in part by NSF, grant number CMMI-1333044. The SEM images were made possible through the NSF MRI grant DMR-1429674.

Acknowledgments: Y.X.G. acknowledges the California State Polytechnic University Pomona 2017-2018 and 2018-2019 Provost's Teacher-Scholar support. We appreciate Mr. Anan Hamdan for his assistance in the SEM operation. Finally, we thank the two reviewers for providing constructive comments on improving the quality of the paper.

Conflicts of Interest: The authors declare no conflict of interest.

\section{References}

1. Bai, P.; Yang, X.; Shen, X.; Zhang, X.; Li, Z.; Yin, Q.; Jiang, G.; Yang, F. Sound absorption performance of the acoustic absorber fabricated by compression and microperforation of the porous metal. Mater. Des. 2019, 167, 107637. [CrossRef]

2. Renterghem, T.V.; Ginderachter, I.V.; Thomas, P. Porous stones increase the noise shielding of a gabion. Appl. Acoust. 2019, 145, 82-88. [CrossRef]

3. Otaru, A.J. Enhancing the sound absorption performance of porous metals using tomography images. Appl. Acoust. 2019, 143, 183-189. [CrossRef]

4. Xu, C.; Mao, Y. Experimental investigation of metal foam for controlling centrifugal fan noise. Appl. Acoust. 2016, 104, 182-192. [CrossRef]

5. Yang, X.; Yu, J.; Guo, Z.; Jin, L.; He, Y.L. Role of porous metal foam on the heat transfer enhancement for a thermal energy storage tube. Appl. Energy 2019, 239, 142-156. [CrossRef]

6. Takai, K.; Yuki, K.; Yuki, K.; Kibushi, R.; Unno, N.; Tanaka, T. Heat transfer performance of an energy-saving heat removal device with uni-directional porous copper for divertor cooling. Fusion Eng. Des. 2018, 136, 518-521. [CrossRef]

7. Park, S.-H.; Kim, T.H.; Jeong, J.H. Experimental investigation of the convective heat transfer coefficient for open-cell porous metal fins at low Reynolds numbers. Int. J. Heat Mass Transf. 2016, 100, 608-614. [CrossRef]

8. Liu, W.; Canfield, N. Development of thin porous metal sheet as micro-filtration membrane and inorganic membrane support. J. Membr. Sci. 2012, 409, 113-126. [CrossRef]

9. Kazemi, A.S.; Patterson, B.; LaRue, R.J.; Papangelakis, P.; Yoo, S.M.; Ghosh, R.; Latulippe, D.R. Microscale parallel-structured, cross-flow filtration system for evaluation and optimization of the filtration performance of hollow-fiber membranes. Sep. Purif. 2019, 215, 299-307. [CrossRef]

10. Wang, Z.; Zhao, C.; Pan, Z. Porous bead-on-string poly (lactic acid) fibrous membranes for air filtration. J. Colloid Interface Sci. 2015, 441, 121-129. [CrossRef] [PubMed]

11. Michailidis, N.; Stergioudi, F.; Tsouknidas, A. Deformation and energy absorption properties of powder-metallurgy produced $\mathrm{Al}$ foams. Mater. Sci. Eng. A 2011, 528, 7222-7227. [CrossRef] 
12. Gan, Y.X.; Dong, J.; Gan, J.B. Carbon network/aluminum composite made by powder metallurgy and its corrosion behavior in seawater. Mater. Chem. Phys. 2017, 202, 190-196. [CrossRef]

13. Jones, D.A. Principles and Prevention of Corrosion; Prentice Hall: Upper Saddle River, NJ, USA, 1996; pp. 80-96, 144-161, 169-172.

14. Astm, G. Standard test method for conducting potentiodynamic polarization resistance measurements. Annu. Book ASTM Stand. 2009, 3, 237-239.

15. AZO Materials, Aluminium-Specifications, Properties, Classifications and Classes. 2005. Available online: https://www.azom.com/article.aspx?ArticleID=2863 (accessed on 26 May 2019).

16. Mutombo, K.; du Toit, M. Corrosion Fatigue Behaviour of Aluminium 5083-H111 Welded Using Gas Metal Arc Welding Method. Available online: https://www.intechopen.com/books/arc-welding/corrosionfatigue-behaviour-of-aluminium-5083-h111-welded-using-gas-metal-arc-welding-method (accessed on 16 December 2011).

17. Nakajima, H. Fabrication, properties, and applications of porous metals with directional pores. Proc. Jpn. Acad. Ser. B 2010, 86, 884-899. [CrossRef]

18. AZO Materials, Aluminium/Aluminum 6061 Alloy (UNS A96061). 2012. Available online: https://www. azom.com/article.aspx?ArticleID=6636 (accessed on 26 May 2019).

19. Duxbury, A.C.; Byrne, R.H.; Mackenzie, F.T. Seawater. 1998. Available online: https://www.britannica.com/ science/seawater (accessed on 26 May 2019).

20. ASTM G3-89: Standard Practice for Conventions Applicable to Electrochemical Measurements in Corrosion Testing. 2010. Available online: https://compass.astm.org/Standards/HISTORICAL/G3-89R10.htm (accessed on 26 May 2019).

21. ASTM G5-14e1: Standard Reference Test Method for Making Potentiodynamic Anodic Polarization Measurements. 2014. Available online: https://compass.astm.org/EDIT/html_annot.cgi?G5+14e1 (accessed on 26 May 2019).

22. Totten, G.E.; Tiryakioglu, M.; Kessler, O. Encyclopedia of Aluminum and Its Alloys; CRC Press: Boca Raton, FL, USA, 2018; pp. 40-41.

(C) 2019 by the authors. Licensee MDPI, Basel, Switzerland. This article is an open access article distributed under the terms and conditions of the Creative Commons Attribution (CC BY) license (http://creativecommons.org/licenses/by/4.0/). 